\title{
Differential roles of GnRH-I and GnRH-II neurons in the control of the primate reproductive axis
}

\author{
Henry F. Urbanski ${ }^{1,2,3,4}$ * \\ ${ }^{1}$ Division of Neuroscience, Oregon National Primate Research Center, Beaverton, OR, USA \\ 2 Division of Reproductive and Developmental Sciences, Oregon National Primate Research Center, Beaverton, OR, USA \\ ${ }^{3}$ Department of Behavioral Neuroscience, Oregon Health and Science University, Portland, OR, USA \\ ${ }^{4}$ Department of Physiology and Pharmacology, Oregon Health and Science University, Portland, OR, USA
}

\section{Edited by:}

Sally A. Camper, University of

Michigan Medical School, USA

Reviewed by:

Karine Rizzoti, National Institute for

Medical Research, UK

Anne Barlier, University Aix Marseille,

France

*Correspondence:

Henry F. Urbanski, Division of

Neuroscience, Oregon National

Primate Research Center, 505

Northwest 185th Avenue, Beaverton OR 97006, USA.

e-mail: urbanski@ohsu.edu
In vertebrates, gonadotropin-releasing hormone $(\mathrm{GnRH})$ represents the primary neuroendocrine link between the brain and the reproductive axis, and in some species up to three different forms of $\mathrm{GnRH}$ have been detected. Until recently, it had been assumed that humans and non-human primates only express one form ( $\mathrm{GnRH}-\mathrm{I})$, but it is now clear they also express a second form (GnRH-II). GnRH-II, like GnRH-I, is highly effective at stimulating gonadotropin release, both in vitro and in vivo, but the neurons that produce $\mathrm{GnRH}-\mathrm{II}$ are completely distinct from those producing $\mathrm{GnRH}-\mathrm{I}$. Moreover, $\mathrm{GnRH}-\mathrm{Il}$ and $\mathrm{GnRH}-\mathrm{I}$ producing neurons respond very differently to estradiol; specifically, estradiol stimulates $\mathrm{GnRH}-\mathrm{II}$ gene expression in the former and inhibit $\mathrm{GnRH}-\mathrm{I}$ gene expression in the latter. Consequently, the negative feedback action of estradiol may be mediated exclusively by the subpopulation of $\mathrm{GnRH}$ neurons that express $\mathrm{GnRH}-\mathrm{I}$, while the positive feedback action may be mediated exclusively by the subpopulation that expresses $\mathrm{GnRH}$-II. Taken together, these findings raise the possibility that two completely different $\mathrm{GnRH}$ neuronal systems participate in the control of primate reproductive physiology. The primary role of $\mathrm{GnRH}$ I neurons is likely to be focused on the maintenance and modulation of tonic pulsatile $\mathrm{LH}$ release, whereas the primary role of $\mathrm{GnRH}-\mathrm{II}$ neurons is likely to be focused on the generation of the preovulatory LH surge. This functional segregation of the primate neuroendocrine reproductive axis lends itself for novel targeted approaches to fertility control and for treatment of human reproductive disorders.

Keywords: estradiol, gonadotropin-releasing hormone, ovulation, rhesus macaque

\section{THE NEUROENDOCRINE REPRODUCTIVE AXIS}

In its essence, the mammalian neuroendocrine reproductive axis is composed of three main components, which act in a coordinated manner to control the onset of puberty and to subsequently maintain fertility (Silverman et al., 1994; Ojeda et al., 2006). The pulsatile secretion of gonadotropin-releasing hormone ( $\mathrm{GnRH})$ from the hypothalamus stimulates the anterior pituitary gland to release luteinizing hormone ( $\mathrm{LH})$ and follicle-stimulating hormone (FSH). In turn, these two gonadotropins then act on the gonads to stimulate maturation of gametes and to synthesize and secrete sex-steroid hormones. Important neuroendocrine feedback loops also exist. For example, although sex steroids contribute to the development and maintenance of fertility and play a role in other physiological and behavioral functions, they also feedback onto the hypothalamo-pituitary unit to modulate gonadotropin release. There is, however, a conundrum regarding the mechanism by which sex steroids do this. On the one hand, the ovarian steroid estradiol usually exerts a negative feedback action on GnRH and gonadotropin release, which is epitomized by the marked increases in circulating LH and FSH levels that occur at menopause or after ovariectomy (i.e., when estradiol levels are markedly attenuated). On the other hand, around the time of ovulation estradiol appears to exert a positive feedback action, causing the production of a gonadotropin surge, which serves as the ovulatory trigger. The traditional explanation for these two radically different effects of estradiol is that GnRH neurons respond differentially to low and high levels of this sex steroid - negatively when estradiol levels are low and positively when estradiol levels are high. Inherent in this argument, however, is the assumption that the GnRH neurons are relatively homogenous, despite their diffuse distribution pattern, and that individual GnRH neurons have the capacity to show both negative and positive feedback responses. Recent findings, especially from primate studies, suggest that this assumption is inaccurate. Not only have morphologically distinct GnRH neurons been observed in discrete subpopulations, in some species these subpopulations have been shown to express different molecular forms of GnRH. Importantly, different GnRH neuronal subpopulations respond differently to estradiol, suggesting that the negative and positive feedback actions are mediated by two distinctly different neuronal populations. This alternative view of the neuroendocrine reproductive axis lends itself to novel targeted approaches to fertility control and treatment of human reproductive disorders.

\section{HETEROGENEITY IN THE PRIMATE GnRH NEURONAL SYSTEM}

It has generally been assumed that GnRH neurons are all essentially similar in their responses to neurotransmitters. Indeed, this 
is a fundamental assumption that underlies the extensive use of immortalized GnRH neurons for in vitro studies by many researchers, including members of this laboratory (e.g., Urbanski et al., 1996; Olcese et al., 2003; Garyfallou et al., 2006). However, this assumption is questionable because in humans GnRH neurons appear to show three distinct morphological types, based on cell size and GnRH cDNA probe labeling density (Rance et al., 1994; Krajewski et al., 2003): (1) small, heavily labeled, oval, or fusiform neurons, located primarily in the medial basal hypothalamus, ventral preoptic area, and periventricular zone; (2) small, oval, sparsely labeled neurons located in the septum, and dorsal preoptic region and scattered from the bed nucleus of the stria terminalis to the amygdala ("extended amygdala"); and (3) large round neurons ( $>500 \mu \mathrm{m}$ two sectional profile area), intermediate in labeling density, scattered within the magnocellular basal forebrain complex, extended amygdala, ventral pallidum, and putamen. The pronounced differences in morphology, labeling density, and location of the three subtypes suggest that distinct functional subgroups of GnRH neurons exist in the human brain. Similar morphological subtypes have been observed in the brains of rhesus macaques (Urbanski et al., 1996), and it has been shown that the type 1 and type 3 neurons have characteristically distinct biochemical properties (e.g., they differ in their capacity to express glutamate and estrogen receptors). Currently, however, it is unclear whether the type 2 and 3 neuronal subtypes play any physiological role in the control of gonadotropin synthesis.

A second basic assumption, and the one that is most relevant to this hypothesis, is that pituitary gland activity is influenced by a single molecular form of GnRH. Although multiple molecular forms of $\mathrm{GnRH}$ have been identified in non-mammalian vertebrates (Sherwood et al., 1993; Fernald and White, 1999; Dubois et al., 2002; Roch et al., 2011), until recently only one form of this decapeptide was thought to exist in mammals. It now appears that at least a few eutherian mammals, including musk-shrews, treeshrews, and humans express an additional form of GnRH (review: Herbison, 2006). This second form of GnRH is commonly referred to as "chicken GnRH-II," or simply GnRH-II, and it shows 70\% similarity to mammalian GnRH (i.e., GnRH-I) at the amino acid level (Figure 1). The genomic and mRNA structures of GnRH-II resemble those of GnRH-I, although significant differences exist within the GnRH-associated peptide (GAP) regions of the respective genes (not shown); in addition, in humans the two molecules are encoded on different chromosomes (White et al., 1998). HPLC and immunocytochemical studies have shown that GnRH-II also exists in non-human primates (Lescheid et al., 1997), and this has been corroborated through the cloning of GnRH-II cDNA from the monkey brain (GenBank \#228312; Urbanski et al., 1999). Importantly, GnRH-II gene expression has been demonstrated in the hypothalamus of monkeys, and shows a distribution pattern that is distinct from that of GnRH-I (Figure 2). GnRH-I expression has a diffuse expression pattern in the hypothalamus, whereas GnRH-II appears to be concentrated in specific nuclei such as the paraventricular, supraoptic, suprachiasmatic as well as the medial basal hypothalamus. Subsequent studies used double histochemical labeling to show that GnRH-I and GnRH-II are produced by two completely distinct populations of cells (Latimer et al., 2000).

\section{INFLUENCE OF GnRH-II ON GONADOTROPIN RELEASE}

Although several reviews of the mammalian GnRH system, have attempted to explain the physiological role of GnRH-II (Pawson et al., 2003; Terasawa, 2003; Cheng and Leung, 2005; Herbison, 2006; Kah et al., 2007), the physiological function of this most ancient and highly conserved form of GnRH in primates is still unclear. There is some evidence from the musk-shrew and marmoset that GnRH-II plays a role in coordinating reproductive behavior, although these behavioral effects are thought to be mediated by GnRH-II neurons located in the central regions of the midbrain rather than in the forebrain (Kauffman et al., 2005; Barnett et al., 2006). Rhesus macaques, however, show a high level of GnRH-II expression in the hypothalamus as well as in the midbrain (Urbanski et al., 1999; Latimer et al., 2001), which raises the interesting possibility that GnRH-II may contribute to the control of the primate reproductive neuroendocrine axis. Indeed, it has already been shown that GnRH-II is highly effective at stimulating $\mathrm{LH}$ and $\mathrm{FSH}$ release in rhesus monkeys in vivo, and from pituitary culture in vitro (Lescheid et al., 1997; Densmore and Urbanski, 2003; Kada et al., 2003). Furthermore, this activation can be blocked by Antide, a GnRH receptor-1 (GnRHR-1) specific antagonist (Figure 3). Taken together this suggests that both GnRH-I and GnRH-II act through the same receptor to

\section{GnRH-I}

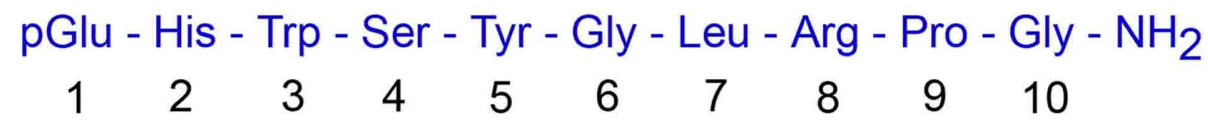
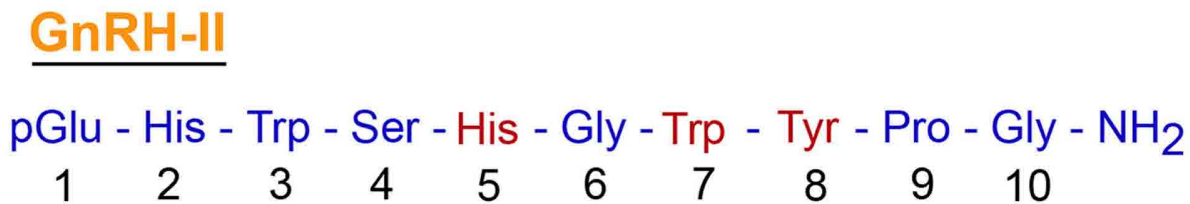

FIGURE 1 | A comparison between the amino acid sequences of GnRH-I and GnRH-II. Both decapeptides undergo similar post-translational modification, which includes conversion of GIn to
pGlu at amino acid position 1 and amidation of the Gly at position 10 . Note, $70 \%$ similarity in the amino acid sequence of the two decapeptides. 


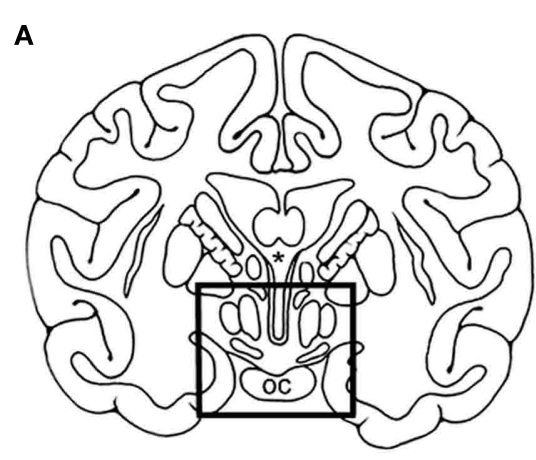

FIGURE 2 | Differential distribution of GnRH-I and GnRH-II mRNA in the rhesus macaque hypothalamus, as revealed by in situ hybridization histochemistry. (A) Line drawing showing hypothalamic region (in box). (B) Autoradiographs showing $\mathrm{GnRH}$ expression in the rostral (upper panels) and

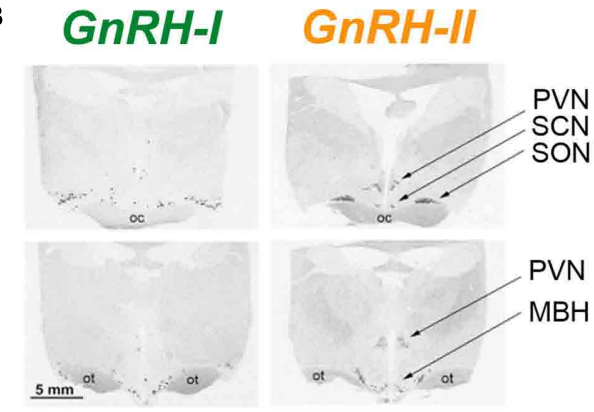

caudal (lower panels) hypothalamic sections. SON, supraoptic nucleus; PVN, paraventricular nucleus; SCN, suprachiasmatic nucleus; $\mathrm{MBH}$, medial basal hypothalamus; oc, optic chiasm; ot, optic tract. (Adapted from Urbanski et al. 1999, with permission from the Endocrine Society).

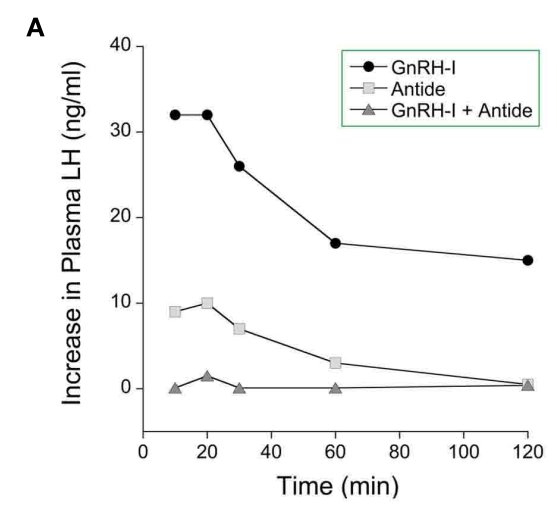

FIGURE 3 | Effect of GnRH on plasma LH levels in female rhesus macaques. $\mathrm{GnRH}-\mathrm{I}$ or $\mathrm{GnRH}-\mathrm{Il}$ (both at $1 \mu \mathrm{g} / \mathrm{kg}$ body weight) were administered via an indwelling vascular catheter, and the effect of $\mathrm{GnRH}$ receptor-1 antagonist was determined by simultaneous administration of
$\mathbf{B}$

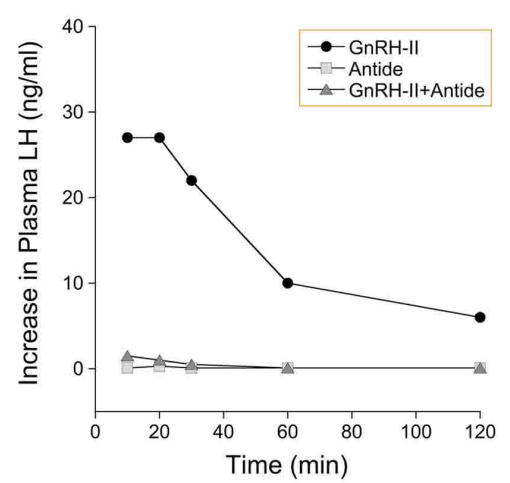

Antide (100 $\mu \mathrm{g} / \mathrm{kg}$ body weight). The data demonstrate that (A) $\mathrm{GnRH}-\mathrm{I}$ and (B) $\mathrm{GnRH}-$ II are both potent stimulators of $\mathrm{LH}$ release and that they both act through the same $\mathrm{GnRH}$ receptor (i.e., GnRH receptor-1). (Adapted from Densmore and Urbanski, 2003, with permission from the Endocrine Society). stimulate gonadotropin release. Note that a second receptor for GnRH (GnRHR-2) has been cloned in monkeys and humans, but it probably does not have a specific role in controlling the reproductive neuroendocrine axis of primates; in monkeys the GnRHR-2 has a ubiquitous distribution pattern, while in humans there is a stop codon in the middle of its gene sequence which precludes its translation into a functional protein (Cheng and Leung, 2005; Herbison, 2006).

\section{DIFFERENTIAL RESPONSES OF GnRH-I AND GnRH-II NEURONS TO ESTRADIOL}

Although GnRH-I and GnRH-II can both stimulate gonadotropin release in the rhesus macaque (Figure 3), the neurons that produce them show marked differences in their responsiveness to estradiol. Firstly, the GnRH-II gene promoter contains estrogen response elements and the GnRH-II neurons express estradiol receptors (ER $\beta$ ), whereas GnRH-I neurons do not (Sullivan et al., 1995; Densmore and Urbanski, 2004). Furthermore, semi-quantitative in situ hybridization histochemistry (Densmore and Urbanski, 2004) has shown that GnRH-II gene expression increases in the monkey medial basal hypothalamus after exposure to estradiol, whereas GnRH-I gene expression decreases (Figure 4). This observation is consistent with the central hypothesis that different GnRH neuronal subpopulations respond differentially to estradiol. Importantly, the result suggests that GnRH-II neurons are the primary mediators of positive estradiol feedback, whereas the GnRH-I neurons are the primary mediators of negative estradiol feedback. It is also consistent with the finding from other primate studies, showing that hypothalamic GnRH-I gene expression is elevated when estradiol levels are very low, such as after menopause or after ovariectomy (Rance and Uswandi, 1996; Abel et al., 1999). Additional support for the hypothesis comes from a microarray gene profiling study that examined hypothalamic GnRH-I and GnRH-II gene expression across the monkey menstrual cycle (Urbanski et al., 2009, 2010a). This study focused on three stages of the menstrual cycle that show three distinct sex-steroid profiles (Figure 5). During the early follicular (EF) phase, both estradiol and progesterone concentrations are low, whereas in the late follicular (LF) phase estradiol is highly elevated; during the mid-luteal (ML) phase, estradiol is moderately 


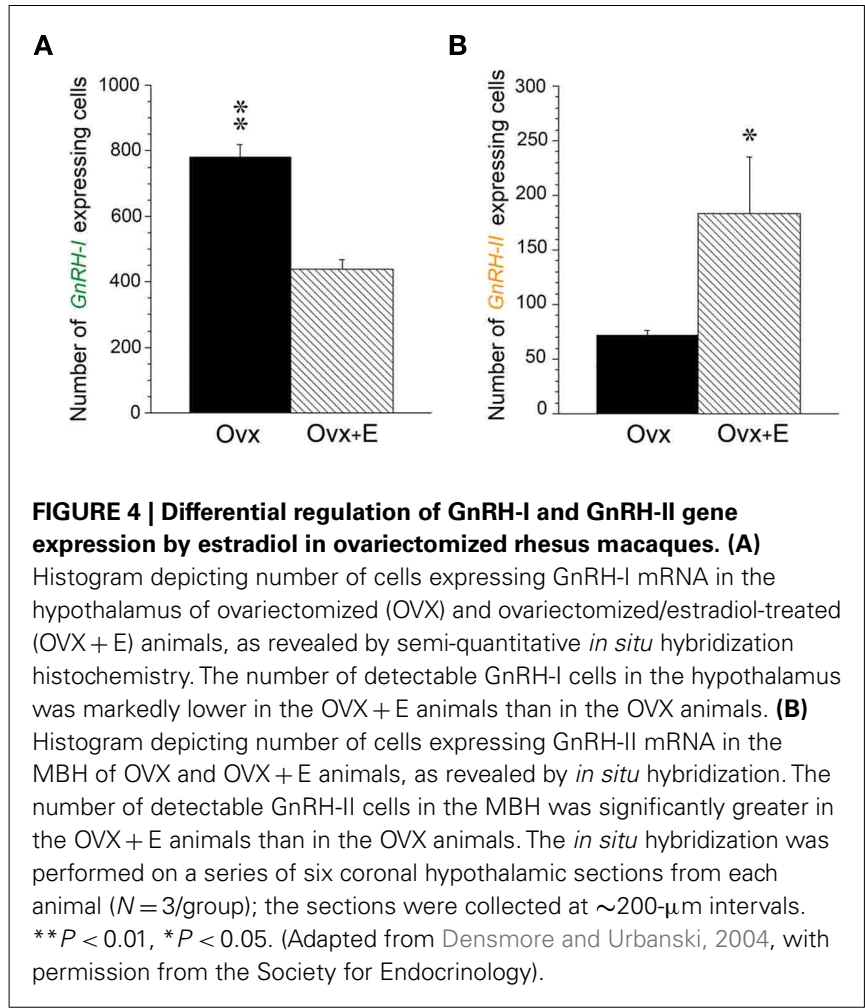

elevated and progesterone highly elevated (Downs and Urbanski, 2006). Despite differences in circulating sex-steroid concentrations during these three phases of the cycle, GnRH-I gene expression showed no significant change (Figure 5A); in marked contrast, GnRH-II gene expression showed a marked increase during the LF phase, in association with the elevated estradiol levels. The positive relationship between estradiol and GnRH-II gene expression, and the close temporal relationship between elevated GnRH-II gene expression and the preovulatory LH surge, suggests that the GnRH-II neurons play a dominant causal role in the preovulatory LH surge (Figure 5B). Further supportive evidence for this hypothesis comes from a recent study in which estradiol benzoate (EB; $42 \mu \mathrm{g} / \mathrm{kg}$, s.c.) was administered to ovariectomized rhesus macaques (Urbanski et al., 2010b). In this well-established experimental model plasma estradiol levels reached a peak within $4 \mathrm{~h}$ of $\mathrm{EB}$ injection, and this was associated with an expected suppression of plasma LH levels, followed by a surge approximately 2 days later. Real-time-PCR showed that initial suppression of $\mathrm{LH}$ to be associated with a decrease in GnRH-I gene expression, which is consistent with estradiol exerting a negative influence on GnRH-I neurons. In marked contrast, GnRH-II gene expression increased following the estradiol peak, and reached a maximum just before the plasma LH surge, which is consistent with estradiol exerting a positive influence on GnRH-II neurons.

\section{CENTRAL HYPOTHESIS}

Based on these recent findings, mainly from rhesus macaques, it is hypothesized that GnRH-II neurons play a major role in the generation of the preovulatory LH surge in female primates,
A
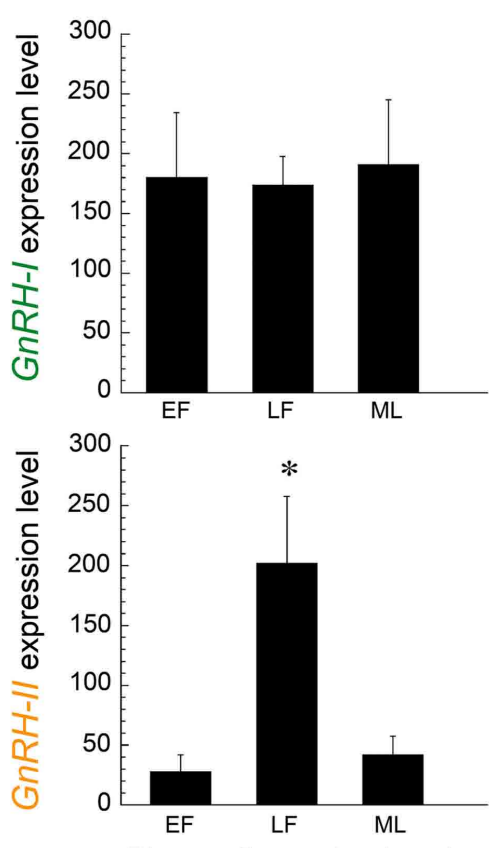

B

Phase of menstrual cycle
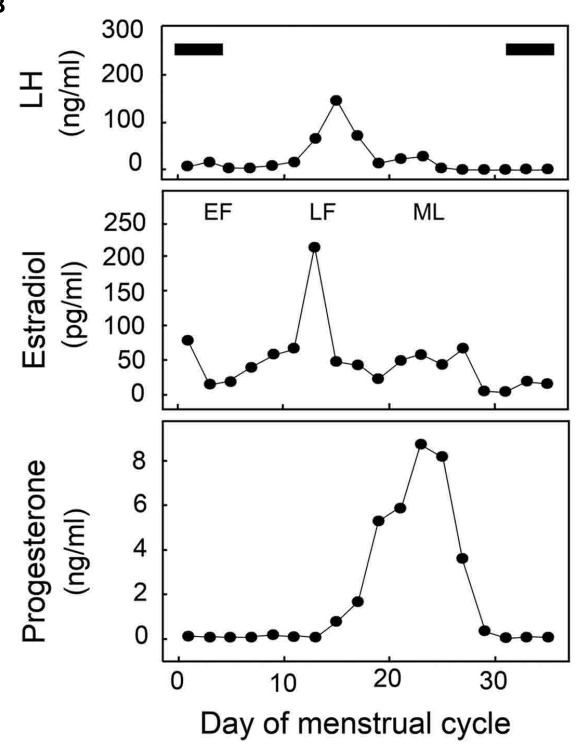

FIGURE 5 | (A) Mean expression of GnRH-I (upper panel) and GnRH-II (lower panel) mRNA levels in the rhesus monkey hypothalamus, as determined by Affymetrix GeneChip microarray analysis (HU133A plus 2.0; $N=3-4$ /group). The following three characteristic stages of the menstrual cycle were examined: $E F$, early follicular; $L F$, late follicular, $M L$, mid-luteal. The level of $\mathrm{GnRH}-\mathrm{I}$ gene expression was similar across the menstrual cycle, whereas the level of $\mathrm{GnRH}-$ II gene expression showed a significant mid-cycle increase $\left({ }^{*} P<0.05\right)$. (B) Serum reproductive hormone profiles from a representative female rhesus macaque across a complete menstrual cycle. Note the temporal relationship between the mid-cycle preovulatory LH surge and the elevated serum estradiol levels of the LF phase. Periods of menstruation are indicated by black horizontal bars. Together the data suggest that estradiol-mediated activation of $\mathrm{GnRH}-$ II neurons may play a key role in triggering ovulation, whereas $\mathrm{GnRH}-\mathrm{I}$ neurons are more likely to play a role in modulating tonic $\mathrm{LH}$ release and in follicular maturation. (Adapted from Urbanski et al., 2010a). 


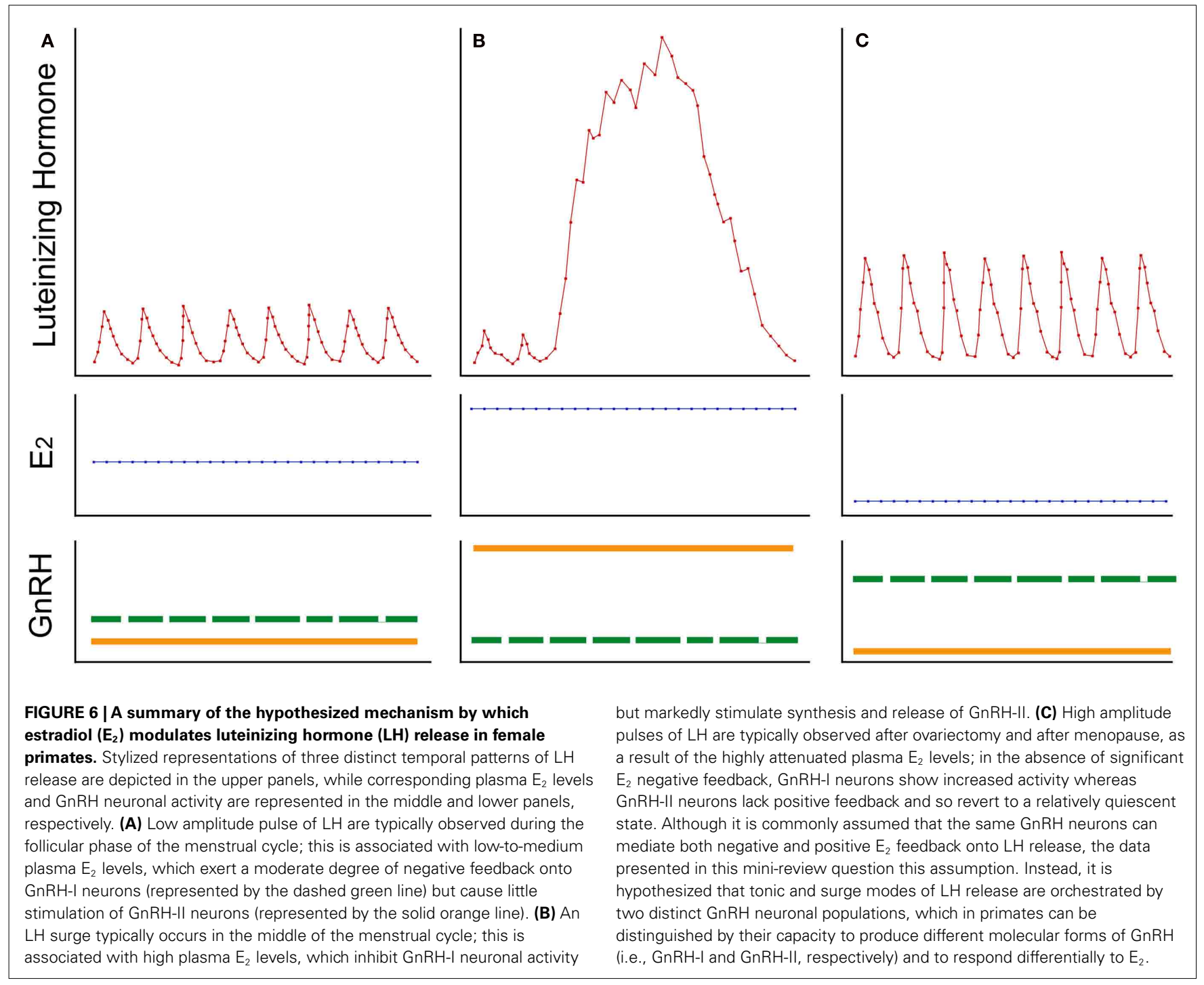

whereas GnRH-I neurons mediate the negative feedback influence of estradiol on tonic gonadotropin release (Figure 6). It should be emphasized that this hypothesis does not invoke a special role for the GnRH-II molecule, other than suggesting that GnRH-II expression may be used to identify the estrogenresponsive neurons that are activated at the time of the $\mathrm{LH}$ surge. The hypothesis simply proposes that the menstrual cycle is orchestrated by the coordinated action of two separate subpopulations of GnRH neurons - one subpopulation responds to estradiol in a negative manner and is involved in stimulating the ovary during the follicular phase of the cycle, while the other subpopulation responds to estradiol in a positive manner and hyper-stimulates the pituitary gland to produce a mid-cycle $\mathrm{LH}$ surge.

In rodents it may be more difficult to distinguish between these two GnRH neuronal subpopulations because only one molecular form of GnRH (i.e., GnRH-I) has been equivocally shown to exist. Despite attempts by several laboratories, GnRH-II has still not been cloned in mice or rats, which is not surprising given that a BLAST search of the genome of these rodents reveals only one molecular form of GnRH (i.e., the traditional GnRH-I). Nevertheless, there is evidence from female rodents that activation of a specific subpopulation of GnRH-I neurons is associated with the preovulatory LH surge (Hiatt et al., 1992; Porkka-Heiskanen et al., 1994; Rubin and King, 1994). Therefore, it is plausible that the essence of the current hypothesis also applies to non-primate mammalian species.

For many years there was much debate as to whether a GnRH surge even existed in primates, because the primate pituitary gland appeared capable of producing an LH surge in response to tonic pulsatile GnRH stimulation (Knobil et al., 1980). Although there is now good evidence to suggest that an estradiol-induced $\mathrm{GnRH}$ surge does occur in primates, as in rodents, the key studies (Xia et al., 1992; Pau et al., 1993) were performed before the existence of GnRH-II was known in primates, and unfortunately relied on hormone immuno-assays that did not clearly distinguish between GnRH-I and the closely related GnRH-II molecule. Consequently, it is unclear if the assays measured GnRH-I exclusively or GnRH-I 
plus GnRH-II. More recently, however, c-Fos immunohistochemistry has been used to examine activation of GnRH-I neurons around the time of the primate preovulatory surge. In marked contrast to rodents (Lee et al., 1990; Hoffman et al., 1993; Doan and Urbanski, 1994), however, there was no obvious increase in the number of c-Fos-expressing GnRH-I neurons at the time of the LH surge in primates (Witkin et al., 1994; Caston-Balderrama et al., 1998). This negative finding gives further credence to the hypothesis that GnRH-I neurons do not play a dominant role in stimulating the preovulatory $\mathrm{LH}$ surge in primates, and implies that this role is more likely to be mediated by GnRH-II neurons instead.

\section{CONCLUDING REMARKS}

Like rhesus macaques, humans express two molecular forms of GnRH (i.e., GnRH-I and GnRH-II). Given that GnRH-I and GnRH-II are produced by different neuronal populations,

\section{REFERENCES}

Abel, T. W., Voytko, M. L., and Rance, N. E. (1999). The effects of hormone replacement therapy on hypothalamic neuropeptide gene expression in a primate model of menopause. J. Clin. Endocrinol. Metab. 84, 2111-2118.

Barnett, D. K., Bunnell, T. M., Millar, R. P., and Abbott, D. H. (2006). Gonadotropin-releasing hormone II stimulates female sexual behavior in marmoset monkeys. Endocrinology 147, 615-623.

Caston-Balderrama, A. L., Cameron, J. L., and Hoffman, G. E. (1998). Immunocytochemical localization of Fos in perfused nonhuman primate brain tissue: fixation and antisera selection. J. Histochem. Cytochem. 46, 547-556.

Cheng, C. K., and Leung, P. C. K. (2005). Molecular biology of gonadotropin-releasing hormone (GnRH)-I, GnRH-II, and their receptors in humans. Endocr. Rev. 26, 283-306.

Densmore, V. S., and Urbanski, H. F. (2003). Relative effects of GnRHI and GnRH-II on gonadotropin release. J. Clin. Endocrinol. Metab. 88, 2126-2134.

Densmore, V. S., and Urbanski, H. F. (2004). Effect of estradiol on hypothalamic GnRH-II gene expression in the female rhesus macaque. J. Mol. Endocrinol. 33, 145-153.

Doan, A., and Urbanski, H. F. (1994). Diurnal expression of Fos-related proteins in LHRH neurons of Syrian hamsters. Biol. Reprod. 50, 301-308.

Downs, J. L., and Urbanski, H. F. (2006). Neuroendocrine changes in the aging reproductive axis of female rhesus macaques (Macaca mulatta). Biol. Reprod. 75, 539-546.

Dubois, E. A., Zandbergen, M. A., Peute, J., and Goos, H. J. (2002).
Evolutionary development of three gonadotropin-releasing hormone $(\mathrm{GnRH})$ systems in vertebrates. Brain Res. Bull. 57, 413-418.

Fernald, R. D., and White, R. B. (1999). Gonadotropin-releasing hormone genes: phylogeny, structure, and functions. Front. Neuroendocrinol. 20, 224-240.

Garyfallou, V. T., Lemos, D., and Urbanski, H. F. (2006). Expression profiling of genes associated with glutamate and GABA neurotransmission in immortalized GT1-1, GT1-7, and Gn10 cells. Brain Res. 1086, 50-54.

Herbison, A. E. (2006). "Physiology of the gonadotropin-releasing hormone neuronal network," in Physiology of Reproduction, eds E. Knobil and J. D. Neill (New York: Raven Press), 1415-1482.

Hiatt, E. S., Brunetta, P. G., Seiler, G. R., Barney, S. A., Selles, W. D., Wooledge, K. H., and King, J. C. (1992). Subgroups of luteinizing hormone-releasing hormone perikarya defined by computer analyses in the basal forebrain of intact female rats. Endocrinology 130, 1030-1043.

Hoffman, G. E., Smith, M. S., and Verbalis, J. G. (1993). C-Fos and related immediate early gene products as markers of activity in neuroendocrine systems. Front. Neuroendocrinol. 14, 173-213.

Kada, Y., Murota-Kowano, A., Kakar, S. S., and Winter, S. J. (2003). Evidence that gonadotropin-releasing hormone-II stimulates luteinizing hormone and follicle-stimulating hormone secretion from monkey pituitary culture by activating the gonadotropin-releasing hormone-I receptor. Biol. Reprod. 69, 1356-1361.

Kah, O., Lethimonier, C., Somoza, G., Guilgur, L. G., Vaillant, C., and

it is plausible that fertility in women is controlled by the coordinated action of two distinct GnRH neuronal subpopulations, rather than by a single homogenous population. If correct, this hypothesis has several implications, especially in primates where the distinct biochemical signatures of the two subpopulations lend themselves to targeted therapeutic interventions. For example, specific activation of the GnRH-II neurons could help to treat amenorrhea and improve fertility. Conversely, by specific silencing of the GnRH-II neurons it may be possible to selectively block ovulation while retaining normal tonic LH secretion, a strategy that could open up novel approaches to contraception without negatively impacting ovarian steroidogenesis.

\section{ACKNOWLEDGMENTS}

This work was supported by NIH grants AG-029612, HD-029186, and RR-000163.

Lareyre, J. J. (2007). GnRH and GnRH receptors in metazoa: a historical comparative, and evolutive perspective. Gen. Comp. Endocrinol. 153, 346-364.

Kauffman, A. S., Wills, A., Millar, R. P. and Rissman, E. F. (2005). Evidence that the type-2 gonadotrophinreleasing hormone $(\mathrm{GnRH})$ receptor mediates the behavioural effects of GnRH-II on feeding and reproduction in musk shrews. J. Neuroendocrinol. 17, 489-497.

Knobil, E., Plant, T. M., Wildt, L., Belchetz, P. E., and Marshall, G. (1980). Control of the rhesus menstrual cycle: permissive role of hypothalamic gonadotropinreleasing hormone. Science 207, 1371-1373.

Krajewski, S. J., Abel, T. W., Voytko, M. L., and Rance, N. E. (2003). Ovarian steroids differentially modulate the gene expression of gonadotropin-releasing hormone neuronal subtypes in the ovariectomized cynomolgus monkey. J. Clin. Endocrinol. Metab. 8 8655-8662.

Latimer, V. S., Kohama, S. G., Garyfallou, V. T., and Urbanski, H. F. (2001). A developmental increase in the expression of mRNA encoding a second form of gonadotropinreleasing hormone (GnRH-II) in the primate hypothalamus. J. Clin. Endocrinol. Metab. 86, 324-329.

Latimer, V. S., Rodrigues, S. M., Garyfallou, V. T., Kohama, G., White, R. B., Fernald, R. D., and Urbanski, H. F. (2000). Two molecular forms of gonadotropin-releasing hormone (GnRH-I and GnRH-II) are expressed by two separate populations of cells in the rhesus macaque hypothalamus. Mol. Brain Res. Brain Res. 75, 287-292.
Lee, W. S., Smith, M. S., and Hoffman, G. E. (1990). Luteinizing hormone-releasing hormone neurons express Fos protein during the proestrus surge of luteinizing hormone. Proc. Natl. Acad. Sci. U.S.A. 87, 5163-5167.

Lescheid, D. W., Terasawa, E., Quanbeck, C., Urbanski, H. F., Warby, C. M., and Sherwood, N. M. (1997). A second form of gonadotropinreleasing hormone is present in the primate brain. Endocrinology 138, 5618-5629.

Ojeda, S. R., Lomniczi, A., Mastronardi, C., Heger, S., Roth, C., Parent, A. S., Matagne, V., and Mungenast, A. (2006). Minireveiw: the neuroendocrine regulation of puberty: is the time ripe for a systems biology approach? Endocrinology 147, 1166-1174.

Olcese, J., Domagalski, R., Bednorz, A., Weaver, D. R., Urbanski, H F., Reuss, S., and Middendorff, R. (2003). Expression and regulation of mPerl in immortalized GnRH neurons. Neuroreport 14, 613-618.

Pau, K. F., Berria, M., Hess, D. L., and Spies, H. G. (1993). Preovulatory gonadotropin-releasing hormone surge in ovarian-intact rhesus macaques. Endocrinology 133, 1650-1656.

Pawson, A. J., Morgan, K. M., Maudsley, S. R., and Millar, R. P. (2003). Type II gonadotrophin-releasing hormone (GnRH-II) in reproductive biology. Reproduction 126, 271-278.

Porkka-Heiskanen, T., Urban, J. H. Turek, F. W., and Levine, J. E. (1994). Gene expression in a subpopulation of luteinizing hormone-releasing hormone (LHRH) neurons prior to the preovulatory gonadotropin surge. J. Neurosci. 14, 5548-5558. 
Rance, N. E., and Uswandi, S. V. (1996). Gonadotropin-releasing hormone gene expression is increased in the medial basal hypothalamus of postmenopausal women. J. Clin. Endocrinol. Metab. 81, 3540-3546.

Rance, N. E., Young, W. S. III, and McMullen, N. T. (1994). Topography of neurons expressing luteinizing hormone-releasing hormone gene transcripts in the human hypothalamus and basal forebrain. J. Comp. Neurol. 4, 573-586.

Roch, G. J., Busby, E. R., and Sherwood, N. M. (2011). Evolution of GnRH: diving deeper. Gen. Comp. Endocrinol. 171, 1-16.

Rubin, B. S., and King, J. C. (1994). The number and distribution of detectable luteinizing hormone (LH)-releasing hormone cell bodies changes in association with the preovulatory LH surge in the brains of young but not middle-aged female rats. Endocrinology 134, 467-474.

Sherwood, N. M., Lovejoy, D. A., and Coe, I. R. (1993). Origin of mammalian gonadotropinreleasing hormones. Endocr. Rev 14, 241-254.

Silverman, A. J., Livne, I., and Witkin, J. W. (1994). “The gonadotropin releasing hormone (GnRH), neuronal systems: immunocytochemistry and in situ hybridization," in Physiology of Reproduction, eds E. Knobil and J. D. Neill (New York: Raven Press), 1683-1709.

Sullivan, K. A., Witkin, J. W., Ferin, M., and Silverman, A.-J. (1995). Gonadotropin-releasing hormone neurons in the rhesus macaques are not immunoreactive for estrogen receptor. Brain Res. 685, 198-200.

Terasawa, E. (2003). Gonadotropinreleasing hormone II: is this neuropeptide important for mammalian reproduction? Endocrinology 144, 3-4.

Urbanski, H. F., Eghlidi, D., Brown, D. I., Noriega, N. C., and Kohama, S. G. (2009). Positive feedback of estrogen on GnRH-II gene expression in the rhesus macaque hypothalamus. Soc. Neurosci. Abstr. 35, abstr. 703.11.

Urbanski, H. F., Eghlidi, D. H., and Kohama, S. G. (2010a). Differential effects of oestrogen on hypothalamic GnRH-I and GnRH-II gene expression in female rhesus macaques. Endocr. Abstr. 21, OC2.5.

Urbanski, H. F., Eghlidi, D. H., and Kohama, S. G. (2010b). Evidence that the primate menstrual cycle is regulated by the coordinated action of two distinct GnRH neuronal populations. Biol. Reprod. 83(suppl.), abstr. 578.

Urbanski, H. F., Kohama, S. G., and Garyfallou, V. T. (1996). Mechanisms mediating the response of GnRH neurones to excitatory amino acids. Rev. Reprod. 1, 173-181.

Urbanski, H. F., White, R. B., Fernald, R. D., Kohama, S. G., Garyfallou, V. T., and Densmore, V. S. (1999). Two distinct molecular forms of gonadotropin-releasing hormone in the brain of rhesus macaques. Endocrinology 140, 1945-1948.

White, R. B., Eisen, J. A., Kasten, T. L., and Fernald, R. D. (1998). Second gene for gonadotropinreleasing hormone in humans. Proc. Natl. Acad. Sci. U.S.A. 95, 305-309.

Witkin, J. W., Xiao, E., Popilskis, S., Ferin, M., and Silverman, A. (1994). Fos expression in the gonadotropinreleasing hormone ( $\mathrm{GnRH}$ ) neuron does not increase during the ovarian steroid-induced GnRH surge in the rhesus monkey. Endocrinology 135, 956-961.

Xia, L., Van Vugt, D., Alston, E. J., Luckhaus, J., and Ferin, M. (1992).
A surge of gonadotropin-releasing hormone accompanies the estradiolinduced gonadotropin surge in the rhesus monkey. Endocrinology 131, 2812-2820.

Conflict of Interest Statement: The author declares that the research was conducted in the absence of any commercial or financial relationships that could be construed as a potential conflict of interest.

Received: 20 October 2011; paper pending published: 28 November 2011; accepted: 23 January 2012; published online: 07 February 2012

Citation: Urbanski HF (2012) Differential roles of GnRH-I and GnRH-II neurons in the control of the primate reproductive axis. Front. Endocrin. 3:20. doi: 10.3389/fendo.2012.00020

This article was submitted to Frontiers in Genomic Endocrinology, a specialty of Frontiers in Endocrinology.

Copyright (c) 2012 Urbanski. This is an open-access article distributed under the terms of the Creative Commons Attribution Non Commercial License, which permits non-commercial use, distribution, and reproduction in other forums, provided the original authors and source are credited. 